\title{
FAKTOR-FAKTOR YANG BERPENGARUH SIGNIFIKAN TERHADAP INDEKS PEMBANGUNAN MANUSIA DI PROVINSI PAPUA
}

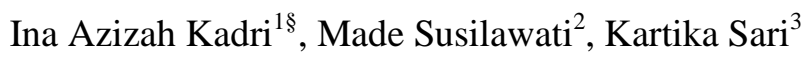 \\ ${ }^{1}$ Program Studi Matematika, Fakultas MIPA - Universitas Udayana [Email: inaazizah5@gmail.com] \\ ${ }^{2}$ Program Studi Matematika, Fakultas MIPA - Universitas Udayana [Email: mdsusilawati@unud.ac.id] \\ ${ }^{3}$ Program Studi Matematika, Fakultas MIPA - Universitas Udayana [Email: sarikaartika@unud.ac.id] \\ ${ }^{\S}$ Corresponding Author
}

\begin{abstract}
Geographically weighted regression $(G W R)$ analysis is one of an analysis to resolve the problem with data contains effect of spatial heterogenity. One of the problems which considers spatial heterogeneity is human development index (HDI). HDI is an indicator that used to measure success in building quality of human life. One of the provinces with the lowest HDI in Indonesia is Papua. The purpose of this research is to know the contribution of each HDI factors in Papua using GWR method. The weighting function used is adaptive gaussian kernel. The results of this research showed HDI's dominant factors in Papua, expected years of schooling and mean years of schooling.
\end{abstract}

Keywords: geographically weighted regression (GWR), spatial heterogeneity, HDI.

\section{PENDAHULUAN}

Indeks pembangunan manusia (IPM) adalah indikator yang digunakan untuk mengukur kualitas hidup manusia. Pencapaian angka IPM memberikan indikasi peningkatan atau penurunan kinerja pembangunan manusia. Salah satu provinsi di Indonesia dengan capaian IPM terendah adalah Provinsi Papua. Berdasarkan data BPS 2017, IPM di Provinsi Papua pada tahun 2016 hanya mencapai 58,08 (kurang dari 60). Angka ini meningkat sebesar 0,8 dari tahun sebelumnya. Namun meskipun mengalami peningkatan, IPM di Provinsi Papua masih dalam kategori rendah.

Faktor - faktor yang memengaruhi capaian IPM di setiap wilayah berbeda - beda. Hal ini disebabkan karena adanya perbedaan karakteristik suatu wilayah dengan wilayah lain. Perbedaan karakteristik antarwilayah menimbulkan efek spasial atau disebut heterogenitas spasial. Salah satu metode untuk mengatasi masalah spasial tersebut adalah metode geographically weighted regression (GWR) (Fotheringham, et al., 2002).

Secara umum model GWR dapat ditulis sebagai

$$
y_{i}=\beta_{0}\left(u_{i}, v_{i}\right)+\sum_{k=1}^{p} \beta_{k}\left(u_{i}, v_{i}\right) x_{i k}+\varepsilon_{i} .
$$

dengan $i$ menyatakan lokasi amatan $(i=$ $1,2,3, \cdots, n), \quad n$ menyatakan banyaknya pengamatan, $y_{i}$ menyatakan variabel terikat pada pengamatan ke- $i, x_{i k}$ merupakan variabel bebas ke- $k$ pada pengamatan ke- $i$, $\beta_{0}$ dan $\beta_{k}$ merupakan parameter regresi ke- $k$ untuk $k=1,2, \ldots, p, \beta_{0}\left(u_{i}, v_{i}\right)$ menyatakan konstanta regresi pada lokasi ke- $i$, $\beta_{k}\left(u_{i}, v_{i}\right) x_{i k}$ menyatakan koefisien regresi pada lokasi ke- $i$ dengan variabel bebas ke- $k, u_{i}$ sebagai titik koordinat spasial (lintang) untuk pengamatan ke- $i \quad v_{i}$ sebagai titik koordinat spasial (bujur) untuk pengamatan ke- $i$ dan $\varepsilon_{i}$ merupakan error yang berdistribusi normal $N\left(0, \sigma^{2}\right)$ pada pengamatan ke- $i$.

Hal yang paling mendasar pada GWR adalah kedekatan antarwilayah yang ditunjukkan melalui matriks pembobot. Fungsi pembobot yang digunakan dalam penelitian ini adalah adaptive kernel gaussian. Fungsi ini memiliki bandwidth yang berbeda untuk setiap lokasi pengamatan (Fotheringham, et al., 2002).

Metode GWR merupakan metode yang sering digunakan untuk masalah spasial. Susanti dkk. (2016) juga melakukan penelitian 
tentang pemodelan tingkat kesejahteraan penduduk Provinsi Kalimantan Selatan menggunakan geographically weighted regression. Penelitian tersebut menghasilkan bahwa faktor-faktor yang berpengaruh secara signifikan adalah tingkat melek huruf penduduk, tingkat partisipasi sekolah, dan presentase balita kekurangan gizi. Penelitian sebelumnya terkait IPM dilakukan oleh Widyastuti dkk. (2018) yang meneliti indeks pembangunan manusia di Kalimantan menggunakan geographically weighted logistic regression. Penelitian tersebut menghasilkan bahwa faktor-faktor yang berpengaruh secara signifikan untuk IPM di Kalimantan adalah persentase penduduk miskin, persentase pengangguran terbuka, persentase penduduk yang lulus perguruan tinggi dan banyaknya jumlah tenaga kesehatan (dokter, bidan, perawat dan apoteker).

\section{METODE PENELITIAN}

Data yang digunakan pada penelitian ini adalah data sekunder mengenai Indeks Pembangunan Manusia (IPM) untuk setiap Kabupaten/Kota di Papua yang bersumber dari Badan Pusat Statistik (BPS) tahun 2017 Provinsi Papua.

Variabel yang digunakan meliputi variabel terikat $(Y)$ yaitu indeks pembangunan manusia di Provinsi Papua dan variabel bebas (X). Variabel bebas $(\mathrm{X})$ antara lain angka harapan hidup $\left(X_{1}\right)$, harapan lama sekolah $\left(X_{2}\right)$, rata rata lama sekolah $\left(X_{3}\right)$, dan pengeluaran per kapita $\left(X_{4}\right)$

Langkah-langkah yang dilakukan adalah

1. Mengumpulkan data mengenai indeks pembangunan manusia di masing-masing Kabupaten/Kota yang di kategorikan sebagai variabel terikat (Y) dan keempat variabel bebasnya serta data geografis letak titik koordinat masing-masing Kabupaten/ Kota di Papua.

2. Memodelkan indeks pembangunan manusia menggunakan regresi linear berganda.

$y_{i}=\beta_{0}+\beta_{1} x_{i 1}+\beta_{2} x_{i 2}+\cdots+$

$\beta_{p} x_{i p}+\varepsilon_{i}$

3. Memeriksa kenormalan dari residual menggunakan uji Anderson Darling dengan hipotesis:

$H_{0}$ : Residual berdistribusi normal

$H_{1}$ : Residual tidak berdistribusi normal

Statistik uji yang digunakan adalah

$$
\begin{gathered}
A^{2}=-n-\frac{1}{n} \sum_{i=1}^{n}(2 i-1)\left\{\ln F\left(Y_{i}\right)+\right. \\
\ln \left[1-F\left(Y_{n+1+i}\right)\right\}
\end{gathered}
$$

dengan $F\left(Y_{i}\right)$ menyatakan fungsi sebaran kumulatif dari normal baku dan $Y_{i}$ menyatakan data yang diurutkan (Algifari, 2000).

Keputusan: Terima $H_{0}$ pada taraf signifikasi $\alpha$ jika $A^{2}<A D_{\text {tabel }}$ atau $p_{\text {value }} \geq \alpha$. Jika tidak normal, maka dilakukan transformasi data.

4. Memeriksa multikolinearitas dari variabelvariabel bebas dengan melihat nilai $V I F$ pada setiap variabel bebas. Jika nilai VIF > 5 maka terdapat multikolinearitas. Salah satu metode yang dapat digunakan untuk mengatasi multikolinearitas adalah metode stepwise. Statistik uji yang digunakan adalah

$V I F_{j}=\frac{1}{1-R_{j}^{2}}$

dengan $R_{j}^{2} \quad$ merupakan koefisien determinasi antara $X_{j}$ dengan variabel prediktor lainnya pada model regresi dengan $j=1,2, \ldots, p$. Jika terdapat multikolinearitas, maka pada penelitian ini digunakan metode stepwise (Draper \& Smith, 1992).

5. Memeriksa heteroskedastisitas pada residual menggunakan uji Breush Pagan (Anselin, 1988) dengan hipotesis uji: $H_{0}:{\sigma_{1}}^{2}={\sigma_{2}}^{2}=\cdots={\sigma_{n}}^{2}=\sigma^{2}$ (Tidak terjadi heteroskedastisitas pada data). $H_{1}$ : Minimal ada satu ${\sigma_{i}}^{2} \neq \sigma^{2}$ (Terjadi heteroskedastisitas pada data).

Statistik uji yang digunakan adalah

$B P=\frac{1}{2} \boldsymbol{f}^{T} \boldsymbol{X}\left(\boldsymbol{X}^{\boldsymbol{T}} \boldsymbol{X}\right)^{-\mathbf{1}} \boldsymbol{X}^{\boldsymbol{T}} \boldsymbol{f}$

dengan $\boldsymbol{f}$ menyatakan vektor berukuran $(n \times 1)$ yang berisi $\boldsymbol{f}=\left[f_{1}, f_{2}, \ldots, f_{n}\right]$ dengan

$f_{i}=\frac{e_{i}^{2}}{\hat{\sigma}^{2}}-1$

$\hat{\sigma}^{2}=\sum_{i=1}^{n} e_{i}^{2}$

$e_{i}^{2}=\sum_{i=1}^{n}\left(Y_{i}-\widehat{Y}_{l}\right)^{2}$

Notasi $B P$ menyatakan nilai Breusch Pagan, $\hat{\sigma}^{2}$ menyatakan varian sisaan, dan $e_{i}{ }^{2}$ menyatakan nilai kuadrat sisaan.

Keputusan: Tolak $H_{0}$ apabila nilai $B P \geq$ $\chi_{k}{ }^{2}$ dengan taraf signifikan $\alpha$ atau $p_{\text {value }}<\alpha(0,05)$.

Jika tidak terjadi heteroskedastisitas maka berhenti di langkah ini. 
6. Membentuk model geographically weighted regression (GWR) berdasarkan persamaan berikut

$y_{i}=\beta_{0}\left(u_{i}, v_{i}\right)+\sum_{k=1}^{p} \beta_{k}\left(u_{i}, v_{i}\right) x_{i k}+\varepsilon_{i}$

(5)

a. Menentukan $u_{i}$ dan $v_{i}$ berdasarkan garis lintang selatan dan garis bujur timur untuk Kabupaten/Kota $i$ di Papua.

b. Menghitung jarak Euclid antarkabupaten dan kota berdasarkan letak geografis menggunakan rumus:

$d_{i j}=\sqrt{\left(u_{i}-u_{j}\right)^{2}+\left(v_{i}-v_{j}\right)^{2}}$

c. Menentukan nilai bandwidth berdasarkan nilai $\mathrm{CV}$ menggunakan rumus

$C V=\sum_{i=1}^{n}\left(y_{i}-\hat{y}_{\neq i}(b)\right)^{2}$

Bandwidth optimum yang digunakan adalah bandwidth dengan nilai CV terkecil.

d. Menentukan matriks pembobot yang entrientrinya menggunakan fungsi adaptive gaussian kernel dengan persamaan

$w_{i j}=\exp -\left[\left(\frac{\frac{d_{i j}}{b_{i}}}{2}\right)^{2}\right]$

e. Menduga parameter model GWR. Pendugaan parameter model GWR dilakukan dengan menggunakan metode weighted least square (WLS).

f. Menguji kesesuaian model GWR dengan uji $\mathrm{F}$ (Fotheringham, et al., 2002) dengan hipotesis

$H_{0}: \beta_{k}\left(u_{i}, v_{i}\right)=\beta_{k}$

$H_{1}$ : Minimal ada satu $\beta_{k}\left(u_{i}, v_{i}\right) \neq \beta_{k}$

Statistik uji yang digunakan adalah

$F_{\text {hitung }}=\frac{\frac{\operatorname{RSS}\left(H_{0}\right)-\operatorname{RSS}\left(H_{1}\right)}{\tau_{1}}}{\frac{\operatorname{RSS}\left(H_{1}\right)}{\delta_{1}}}$

$\operatorname{RSS}\left(H_{0}\right)$ menyatakan jumlah kuadrat sisaan model regresi linear klasik dan $\operatorname{RSS}\left(H_{1}\right)$ menyatakan jumlah kuadrat sisaan model GWR (Leung, et al., 2000).

$F_{\text {tabel }}$ dapat dicari dengan distribusi $F$ menggunakan derajat bebas $d f_{1}=\frac{\tau_{1}^{2}}{\tau_{2}}$ dan $d f_{2}=\frac{\delta_{1}{ }^{2}}{\delta_{2}}$ pada taraf signifikan $\alpha$, $\tau_{i}=\operatorname{tr}\left[(\boldsymbol{I}-\boldsymbol{H})-(\boldsymbol{I}-\boldsymbol{L})^{T}(\boldsymbol{I}-\boldsymbol{L})\right]^{i}$, dan $\delta_{i}=\operatorname{tr}\left[(\boldsymbol{I}-\boldsymbol{L})^{T}(\boldsymbol{I}-\boldsymbol{L})\right]^{i} \quad$ dengan $i=1,2$

Keputusan: Hipotesis $H_{0}$ ditolak jika $F_{\text {hitung }} \geq F_{\text {tabel }}$. Hal ini berarti ada perbedaan signifikan antara model regresi linear dengan GWR. g. Menguji signifikasi parameter model GWR dengan uji t dengan hipotesis

$H_{0}: \beta_{k}\left(u_{i}, v_{i}\right)=0$

$H_{1}$ :Minimal ada satu $\beta_{k}\left(u_{i}, v_{i}\right) \neq 0$

Statistik uji yang digunakan adalah

$t_{\text {hitung }}=\frac{\widehat{\beta}_{k\left(u_{i}, v_{i}\right)}}{\operatorname{SE} \widehat{\beta}_{k\left(u_{i}, v_{i}\right)}}$

dengan

$S E \hat{\beta}_{k\left(u_{i}, v_{i}\right)}=\sqrt{\operatorname{var} \hat{\beta}_{k\left(u_{i}, v_{i}\right)}}=\sqrt{\boldsymbol{C C ^ { T }} \hat{\sigma}^{2}}$

$\boldsymbol{C}=\left(\boldsymbol{X}^{\boldsymbol{T}} \boldsymbol{W}\left(u_{i}, v_{i}\right) \boldsymbol{X}\right)^{-1} \boldsymbol{X}^{\boldsymbol{T}} \boldsymbol{W}\left(u_{i}, v_{i}\right)$

$\hat{\sigma}^{2}=\frac{\sum_{i=1}^{n}\left(Y_{i}-\hat{Y}_{i}\right)^{2}}{\delta_{1}}$

$\hat{\beta}_{k\left(u_{i}, v_{i}\right)}$ menyatakan koefisien regresi pada koordinat letak geografis (lintang, bujur) ke-i dan $S E \hat{\beta}_{k\left(u_{i}, v_{i}\right)}$ menyatakan standar error penduga parameter $\beta_{k}$, $\boldsymbol{C C}^{\boldsymbol{T}} \hat{\sigma}^{2}$ menyatakan matriks varians dan kovarians pada pengamatan ke-i, dan $\hat{\sigma}^{2}$ menyatakan jumlah kuadrat residual dari regresi GWR global.

Nilai $t_{\text {tabel }}$ dapat dicari dengan distribusi $t$ menggunakan derajat bebas $d f=\frac{\delta_{1}{ }^{2}}{\delta_{2}}$ pada taraf signifikan $\alpha$.

Keputusan: Tolak $H_{0}$ jika $t_{\text {hitung }} \geq t_{\text {tabel }}$ dengan taraf signifikan $\alpha$ atau $p_{\text {value }}<\alpha$. Hal ini berarti ada pengaruh signifikan antara variabel bebas dengan variabel terikat.

\section{HASIL DAN PEMBAHASAN}

Gambaran umum mengenai indeks pembangunan manusia di Provinsi Papua disajikan pada Tabel 1.

Tabel 1. Statistika Deskriptif

\begin{tabular}{|r|r|r|r|r|}
\hline Var & \multicolumn{1}{l|}{ Min } & \multicolumn{1}{l|}{ Max } & \multicolumn{1}{c|}{ Mean } & \multicolumn{1}{c|}{ StDev } \\
\hline $\mathrm{Y}$ & 27,87 & 79,23 & 55,76 & 11,70 \\
\hline $\mathrm{X}_{1}$ & 54,60 & 71,93 & 64,47 & 3,95 \\
\hline $\mathrm{X}_{2}$ & 2,64 & 14,98 & 9,86 & 2,99 \\
\hline $\mathrm{X}_{3}$ & 0,71 & 11,15 & 5,75 & 2,99 \\
\hline $\mathrm{X}_{4}$ & 3,97 & 14,78 & 6,83 & 2,57 \\
\hline
\end{tabular}

Tabel 1 memperlihatkan indeks pembangunan manusia (Y) terendah sebesar 27,87. Pada kolom minimum, semua data tersebut berasal dari Kabupaten Nduga. Untuk angka harapan hidup $\left(\mathrm{X}_{1}\right)$ sebesar 54,60 yang artinya tiap bayi yang baru lahir di Kabupaten Nduga memiliki perkiraan rata-rata umur yang diharapkan untuk hidup sebesar 54,60 atau 
sekitar 55 tahun. Harapan lama sekolah $\left(\mathrm{X}_{2}\right)$ sebesar 2,64 bermakna lamanya sekolah yang diharapkan akan dirasakan oleh anak-anak usia 7 tahun di Kabupaten Nduga dimasa mendatang sebesar 2,64 tahun atau hanya lulus kelas $2 \mathrm{SD}$. Selanjutnya rata-rata lama sekolah $\left(\mathrm{X}_{3}\right)$ sebesar 0,71 yang berarti penduduk di Kabupaten Nduga yang berusia 25 tahun ke atas secara rata-rata menempuh pendidikan formal selama 0,71 tahun atau tidak lulus kelas $1 \mathrm{SD}$. Sedangkan untuk pengeluaran per kapita $\left(\mathrm{X}_{4}\right)$ di Kabupaten Nduga sebesar 3,97 yang berarti secara rata-rata pengeluaran penduduk Kabupaten Nduga selama setahun adalah 3,97 juta. Selanjutnya pada penelitian ini, taraf signifikan $(\alpha)$ yang digunakan sebesar (0.05).

Setelah melakukan analisis deskriptif, akan dibentuk model indeks pembangunan manusia di Provinsi Papua menggunakan analisis regresi berganda. Analisis regresi berganda bertujuan untuk mengetahui hubungan variabel bebas dengan variabel terikat. Diperoleh persamaan regresi linear berganda menggunakan software Minitab 17.

$$
\begin{gathered}
\hat{Y}_{i}=-4,127+0,4738 X_{1}+1,473 X_{2}+ \\
1,463 X_{3}+0,9372 X_{4}
\end{gathered}
$$

Persamaan (1) memiliki nilai koefisien korelasi $\left(R^{2}\right)$ sebesar $99,33 \%$. Hal ini berarti variabel bebas mampu menjelaskan indeks pembangunan manusia secara umum sebesar $99,21 \%$. Sisanya sebesar $0,79 \%$ dijelaskan oleh variabel lain di luar model.

Regesi linear mensyaratkan asumsi-asumsi, diantaranya normalitas residual, tidak ada multikolinearitas antarpeubah bebas dan ragam bersifat homogen.

Uji kenormalan ini bertujuan untuk melihat apakah nilai residual berdistribusi normal atau tidak. Hasil uji kenormalan ditampilkan pada Gambar 1.

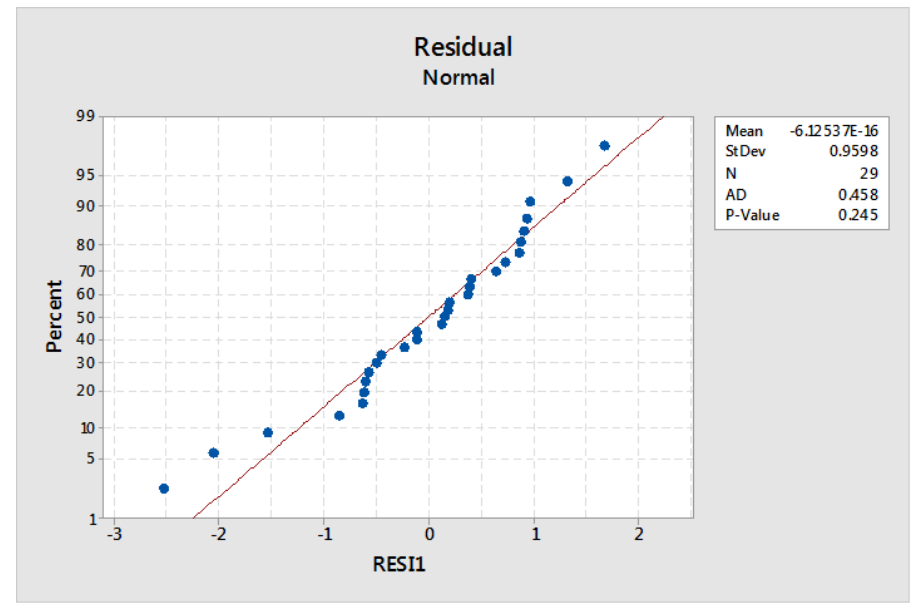

Gambar 1. Uji Kenormalan

Hasil uji Anderson Darling dapat dilihat pada Gambar 1. Tampak bahwa nilai $p_{\text {value }}=$ $0,245 \geq \alpha$. Ini berarti residual yang dihasilkan pada model regresi linear berdistribusi normal.

Pemerikasaan multikoliniearitas dilakukan untuk mengetahui adanya korelasi antarvariabel bebas yang memengaruhi variabel terikat. Hasil uji multikolinearitas dapat dilihat pada Tabel 2 .

Tabel 2. Hasil Uji Multikoliniearitas

\begin{tabular}{|c|c|}
\hline$\left(X_{i}\right)$ & VIF \\
\hline$X_{1}$ & 1,421528 \\
\hline$X_{2}$ & 4,929688 \\
\hline$X_{3}$ & 7,611009 \\
\hline$X_{4}$ & 3,474465 \\
\hline
\end{tabular}

Hasil uji multikoliniearitas pada Tabel 2 adalah terdapat multikoliniearitas antarvariabel bebas. Hal ini ditunjukkan variabel bebas $\mathrm{X}_{3}$ bernilai $\quad V I F \geq 5$. Jika ada gejala multikolinearitas maka diselesaikan menggunakan metode stepwise.

Metode stepwise merupakan gabungan dari metode backward elimination dan metode fordward selection. Kriteria dalam pemilihan variabel yang masuk ke model adalah variabel yang memiliki nilai korelasi tertinggi dan memiliki nilai signifikan yang kurang dari $\alpha$.

Berdasarkan analisis menggunakan metode stepwise diperoleh model terbaik sebagai berikut:

$$
\begin{array}{cr}
\hat{Y}_{i}=-4,128+1,463 X_{3} & +0,474 X_{1} \\
+1,1473 X_{2}+0,937 X_{4} & \text { (12) }
\end{array}
$$


Persamaan tersebut merupakan model terbaik dengan variabel bebas yang berpengaruh signifikan di beberapa kabupaten/kota di Provinsi Papua. Dari model di atas terlihat bahwa semua variabel bebas masuk ke dalam model dan masih terjadi multikolinearitas. Hal ini dapat disimpulkan bahwa kasus multikolinearitas yang terjadi tidak dapat diselesaikan menggunakan metode stepwise. Perlu dilihat variabel $X_{3}$ memiliki korelasi yang tinggi dengan $X_{2}$ yaitu sebesar 0.892. Hal ini menandakan kasus multikolinearitas pada IPM di Provinsi Papua tidak dapat diatasi karena korelasi antarvariabel bebas sangat erat. Untuk selanjutnya dapat digunakan metode analisis komponen utama (AKU), pada penelitian kali ini peneliti hanya menggunaka metode stepwise.

Uji heteroskedastisitas bertujuan untuk mengetahui ada tidaknya ketidaksamaan varian dari residual untuk semua pengamatan.

Hasil uji heteroskedastisitas diperoleh nilai $p_{\text {value }}=0,009189$ lebih kecil dari taraf siginifikasi $\alpha$. Hal ini dapat disimpulkan bahwa terdapat heteroskedastisitas pada data.

Pengaruh heteroskedastisitas menyebabkan model regresi linear perlu dilakukan pemodelan lebih lanjut. Salah satu metode yang dapat digunakan untuk mengatasi heteroskedastisitas yaitu dengan menggunakan metode weighted least regression (WLS).

Memodelkan GWR lokal, peneliti mengambil contoh pada Kabupaten Nduga. Matriks pembobot dalam penelitian ini menggunakan fungsi pembobot kernel adaptive gaussian yang memerlukan jarak Euclid $\left(u_{i j}, v_{i j},\right)$ dan nilai bandwidth tertentu $\left(b_{i}\right)$.

Pemilihan bandwidth optimum dilakukan dengan proses berulang-ulang sehingga memperoleh nilai CV terkecil. Perolehan bandwidth optimum di Kabupaten Nduga sebesar $143,7815 \mathrm{~km}$.

Fungsi pembobot adaptive kernel gaussian untuk Kabupaten Nduga diperoleh dengan persamaan

$$
w_{i j}=\exp \left[-\frac{1}{2}\left(\frac{d_{i j}}{143.7815}\right)^{2}\right]
$$

Model GWR yang terbentuk dari matriks pembobot Kabupaten Nduga adalah

$\widehat{Y}_{\text {Kab.Nduga }}=-5,88314+0,468189 X_{1}$ $+1,688333 X_{2}+1,396168 X_{3}+1,054283 X_{4}$

Dilakukan uji kesesuaian model GWR.
Pengujian ini bertujuan untuk mengetahui ada atau tidak perbedaan yang signifikan antara model regresi linear dengan GWR.

Statistik uji:

$F_{\text {hitung }}=2,726746$

Sedangkan,

$F_{\text {tabel }(0,05 ; 6.277479 ; 17.72252)}=0,255868$

Keputusan:

Hipotesis menolak $H_{0}$ karena $F_{\text {hitung }}=$ $2,726746 \geq F_{\text {tabel }}=0,255868$. Hal ini berarti ada perbedaan signifikan antara model regresi linear dengan GWR. Model GWR lebih layak untuk menggambarkan indeks pembangunan manusia di Provinsi Papua 2017.

Setelah melakukan uji kesesuaian model, dilakukan uji signifikan parameter pada model GWR. Pengujian ini bertujuan untuk mengetahui pengaruh antara variabel bebas dengan variabel terikat pada setiap kabupaten.

Tabel 3. Hasil Uji t Kabupaten Nduga

\begin{tabular}{|c|c|r|}
\hline Variabel & $(\hat{\beta})$ & \multicolumn{1}{|c|}{$t_{\text {hitung }}$} \\
\hline Intersep & $-5,88314$ & $-1,75592$ \\
\hline$X_{1}$ & 0,468189 & 8,44714 \\
\hline$X_{2}$ & 1,688333 & 11,81236 \\
\hline$X_{3}$ & 1,396168 & 6,87777 \\
\hline$X_{4}$ & 0,001054 & 5.52519 \\
\hline
\end{tabular}

Berdasarkan Tabel 3 nilai $t_{\text {hitung }} \geq$ $t_{\text {tabel( } 0,05 ; 25)}=2,059539$ yang berarti menolak $H_{0}$. Variabel bebas yang berpengaruh signifikan untuk indeks pembangunan manusia di Kabupaten Nduga dipengaruhi oleh angka harapan hidup $\left(X_{1}\right)$, harapan lama sekolah $\left(X_{2}\right)$, rata - rata lama sekolah $\left(X_{3}\right)$, dan pendapatan per kapita $\left(X_{4}\right)$.

Setelah diperoleh model GWR untuk masing-masing pengamatan, selanjutnya melakukan interpretasi model GWR. Sebagai contoh interpretasi pada Kabupaten Nduga

$\hat{Y}_{\text {Kab.Nduga }}=-5,88314+0,468189 X_{1}$ $+1,688333 X_{2}+1,396168 X_{3}+1,054283 X_{4}$

Model dapat diartikan jika presentase angka harapan hidup $\left(X_{1}\right)$ bertambah satu tahun dengan menganggap variabel bebas yang lain konstan maka indeks pembangunan manusia akan meningkat sebesar 0,468189 persen. Interpretasi juga berlaku untuk untuk variabel bebas lainnya. Terjadi peningkatan maupun penurunan tergantung variabel bebas yang diperoleh. 


\section{SIMPULAN DAN SARAN}

Faktor-faktor yang berpengaruh signifikan terhadap indeks pembangunan manusia untuk setiap kabupaten dan kota di Provinsi Papua adalah angka harapan hidup $\left(X_{1}\right)$, harapan lama sekolah $\left(X_{2}\right)$, rata-rata lama sekolah $\left(X_{3}\right)$, dan pengeluaran per kapita $\left(X_{4}\right)$. Konstribusi dari masing-masing faktor untuk setiap kabupaten dan kota di Provinsi Papua berbeda-beda. Faktor yang memberikan konstribusinya paling besar untuk semua wilayah adalah faktor pendidikan yang terdiri dari harapan lama sekolah $\left(X_{2}\right)$, rata-rata lama sekolah $\left(X_{3}\right)$. Sedangkan kontribusi yang paling kecil untuk semua wilayah adalah faktor ekonomi berupa pengeluaran per kapita.

Pada penelitian ini, efek multikolinearitas masih belum teratasi. Sehingga untuk peneliti selanjutnya yang akan mengambil kasus yang sama dan terjadi multikolinearitas sebaiknya menggunakan metode analisis komponen utama (AKU). Selain itu, penelitian berikutnya dapat melakukan kajian yang lebih lanjut mengenai variabel bebas yang digunakan serta menggunakan indeks pembangunan manusia yang lebih spesifik seperti tingkat kecamatan agar mendapatkan hasil yang akurat.

\section{DAFTAR PUSTAKA}

Algifari, 2000. Analisis Regresi (Teori, Kasus dan Solusi). 2nd penyunt. Yogyakarta: BPFE.

Anselin, L., 1988. Spatial Econometrics: Methods and Models. Netherland: Kluwer Academic Publisher.

BPS, 2017. Indeks Pembangunan Manusia 2014 Metode Baru. Jakarta: Badan Pusat Statistika.

BPS, 2018. Provinsi Papua Dalam Angka 2018. Jakarta: Badan Pusat Statistika.

Draper, N. R. \& Smith, H., 1992. Applied Regression Analysis. New York: John Wiley and Sons.

Fotheringham, A. S., Brunsdon, C. \& Charlton, M., 2002. Geographically Weighted Regression : Analysis of Spatially Varying Relationship. England: John Wiley and Son.

Leung, Y., Mei, C. L. \& Zhang, W. X., 2000. Statistic Test for Spatial Non-Stationarity
Based on the Geographically Weighted Regression Model. Environment and Planning, A(32), pp. 9-32.

Susanti, D. S., Lestia, A. S. \& Sukmawaty, Y., 2016. Pemodelan Tingkat Kesejahteraan Penduduk Propinsi Kalimantan Selatan dengan Pendekatan Geographically Weighted Regression. Jurnal Eksponensial. I(1), pp. 184-191.

Widyastuti, L., Yuniarti, D. \& Hayati, M. N., 2018. Pemodelan Faktor-Faktor yang Berpengaruh Terhadap Indeks Pembangunan Manusia (IPM) di Kalimantan dengan Geographically Weighted Logistic Regression (GWLR). Jurnal Eksponensial, IX(1), pp. 67-74. 